\title{
Pemberdayaan Masyarakat dalam Pengolahan Limbah Organik
}

\author{
Ahmad Ahid Mudayana ${ }^{1}$, Vera Yuli Erviana ${ }^{1 *}$ dan Iis Suwartini ${ }^{1}$ \\ ${ }^{1}$ Universitas Ahmad Dahlan, Jalan Kapas No.9, Semaki, Kecamatan Umbulharjo, Kota Yogyakarta, Daerah \\ Istimewa Yogyakarta \\ *Email korespondensi: vera.erviana@pgsd.uad.ac.id
}

\begin{abstract}
Abstrak
Pemerintah Kulonprogo berupaya menciptakan desa bebas sampah hal tersebut dibuktikan dengan mendirikan bank sampah sebanyak 100 unit tak terkecuali di Desa Karangsari. Pengelolaan sampah hingga saat ini belum optimal padahal sampah dapat diolah menjadi barang bernilai ekonomis. Keterbatasan pengetahuan dan minimnya keterampilan menjadi kendala dalam pengolahan limbah. Maka dari itu perlu adanya upaya untuk meningkatkan SDM dalam pengelolaan sampah organik maupun anorganik. Pemberdayaan masyarakat menuju desa berbasis sampah di Desa Karangsari Kecamatan Pengasih Kulonprogo bertujuan untuk menciptakan lingkungan yang sehat, membuka lapangan pekerjaan, terciptanya produk unggulan desa ramah lingkungan dan menunjang potensi pariwisata di Kulonprogo sehingga dapat meningkatkan pendapatan masyarakat dan pendapatan daerah. Metode yang digunakan yaitu dengan penyuluhan dan pelatihan kepada masyarakat. Penyuluhan dan pelatihan yang diberikan tentang pengolahan limbah organik dan anorganik berbasis zero waste industry. Konsep zero waste industry terdiri dari reduce (mengurangi), reuse (menggunakan kembali), dan recycle (mendaur ulang). Luaran yang dihasilkan berupa teknik pengelolaan limbah organik dan anorganik berbasis Zero Waste Industry, produk unggulan desa aneka souvenir ramah lingkungan, terbentuknya UMKM, terciptanya lapangan kerja baru dan meningkatkan kesadaran lingkungan.
\end{abstract}

Kata kunci: Pengolahan Limbah, Organik, SDM

\section{Abstract}

The local government of Kulonprogo had been making efforts in realizing a zero-waste village. It was proven by the establishment of waste banks with a total of 100 units with no exception in Karangsari village. However, the waste management had not been optimum despite the fact that the waste could be processed into goods with economic value. The limited knowledge and lack of skills became an obstacle in carrying out the waste management. Therefore, there needed to be efforts to improve the human resources in order to conduct both organic and inorganic waste management. The community empowerment towards zero waste village in Karangsari village, Pengasih sub-district, Kulonprogo aimed at creating a healthy environment, providing employment opportunities, creating featured products of environmentally-friendly village and supporting tourism potentials of Kulonprogo in order to increase the community income as well as the regional income. The methods used in this study were counseling and training. The counseling and training were about zero waste industry-based organic and inorganic waste management system. The zero-waste industry concept consisted of actions to reduce, reuse and recycle. The outputs resulted from the study include zero waste industry-based organic and inorganic waste management technique, village featured products of various environmentally-friendly souvenirs, MSME establishment, new employment opportunities and environmental awareness improvement.

Keywords: Waste Management, Organic, SDM

Format Sitasi: Mudayana, A.A., Erviana, V.Y., \& Suwartini, I. (2019). Pemberdayaan Masyarakat Dalam Pengolahan Limbah Organik. Jurnal Solma, 8(2), 339-347, Doi: http://dx.doi.org/10.29405/solma.v8i2.3697

Diterima: 18 September 2019 | Revisi: 02 Oktober 2019 | Dipublikasikan: 21 Oktober 2019 
(C) 2019. Oleh authors. Lisensi Jurnal Solma, LPPM-Uhamka, Jakarta. Artikel ini bersifat open access yang didistribusikan di bawah syarat dan ketentuan Creative Commons Attribution (CC-BY) license. (http://creativecommons.org/licenses/by/4.0/).

\section{PENDAHULUAN}

Permasalahan sampah diberbagai wilayah di Indonesia saat ini masih menjadi problematika yang belum terselesaikan baik di wilayah perkotaan maupun pedesaan. Keterbatasan lahan tempat pembuangan akhir maupun rendahnya pengetahuan masyarakat akan pengelolaan sampah menjadi salah satu faktornya. Sampah di Kota Yogakarta misalnya volume saat ini mencapai 400 ton per hari (Sari \& Mulasari, 2017). Penelitian yang dilakukan Posmaningsih (2016) memperlihatkan bahwa timbunan sampah di Kota Denpasar per hari mencapai 4.703, $07 \mathrm{~m}^{3}$.

Selain persoalan jumlah sampah, juga ada persolan lain terkait sikap masyarakat dalam mengelola sampah. Penelitian yang dilakukan Riswan, Sunoko, \& Hadiyarto (2011) menunjukkan bahwa ada korelasi yang positif antara pengetahuan dan perilaku dengan cara mengelola sampah. Pengetahuan serta perilaku yang rendah maka cara mengelola sampahpun tidak dilakukan dengan baik. Padahal jika dikelola dengan baik maka sampah dapat memberikan banyak manfaat. Maka, perlu pelibatan peran serta masyarakat serta aspek sosial budaya sehingga sampah dapat dikelola dan termanfaatkan dengan baik (Marliani, 2014).

Desa Karangsari Kecamatan Pengasih Kulonprogo merupakan desa yang dinobatkan sebagai desa teknologi informasi di Kulonprogo. Sejumlah 12 dukuh di Karangsari telah memiliki jaringan internet. Hal tersebut tentunya dapat dijadikan media untuk mengembangkan potensi Desa Karangsari. Desa Karangsari saat ini sedang berbenah mewujudkan cita-cita desa menjadi desa percontohan smart village. Desa karangsari tidak hanya berbenah dalam segi adminitrasi saja melainkan semua aspek kehidupan.

Peningkatan sumber daya manusia menuju smart village perlu dilakukan secara sistematis dan berkelanjutan mengingat Desa Karangsari memiliki berbagai potensi objek wisata yang dapat bersinergi dengan masyarakat untuk meningkatkan perekonomian masyarakat setempat dan pendapatan daerah. Keberadaan Desa Karangsari dikelilingi dengan objek wisata Kalibiru, Taman Jamu Naturindo, Pemandian Clereng, Hutan Kemasyarakatan, Watoe Gembel dan masih banyak lagi yang lainnya. Keberadaan letak geografis Desa Karangsari sangat menguntungkan dari segi ekonomi. Desa karangsari pun memiliki objek wisata yang tidak kalah menarik dengan objek wisata lainnya. Kawasan 
wisata kedepan harus ada peraturan daerah yang mengatur tentang pengelolaan sampah (Sahil, Muhdar, Rohman \& Syamsuri, 2016).

Keberadaan berbagai objek wisata yang berada disekitar desa Karangsari tentunya memberi angin segar bagi industri kerajinan. Desa Karangsari perlu menyiapkan industri kerajinan one product one village dimana kerajinan tersebut akan menjadi ciri khas dan produk unggulan desa. Kerajinan desa Karangsari perlu memiliki keunikan yang tidak dimiliki oleh daerah lain. Hal tersebut tentunya akan menambah keanekaragaman oleholeh khas Desa Karangsari. Selama ini UMKM yang ada di Karangsari baru memproduksi aneka makanan seperti emping, aneka olahan lidah buaya dan aneka olahan dari buah salak.

Salah satu kerajinan yang dapat diolah menjadi produk unggulan desa yaitu aneka kerajinan yang berasal dari limbah organik dan anorganik. Sampah yang hingga saat ini belum dapat diatasi secara optimal baik sampah yang berasal dari objek wisata maupun sampah rumahan dapat diolah menjadi barang bernilai ekonomis.

Kepala dinas lingkungan hidup Suharjoko mengatakan sebanyak 100 unit bank sampah yang ada di Kulonprogo belum maksimal dalam memproses sampah. Ratusan bank sampah itu dinilai baru mampu mereduksi sekitar $10 \%$ dari total debit sampah. Sampah terbanyak berasal dari Kecamatan Pengasih yang menghasilkan 100 meter kubik sampah perhari (Susanto, 2018). Edukasi pengolahan sampah kepada ibu rumah tangga perlu digencarkan agar sampah dapat bernilai ekonomis (Susanto, 2018). Berdasarkan permasalahan tersebut perlu adanya upaya pengelolaan SDM agar dapat bersinergis dengan program pemerintah desa bebas sampah dalam mewujudkan smart village.

Sampah perlu ditangani secara sistematis dan berkelanjutan agar tidak merusak lingkungan. Selama ini sampah hanya ditimbun tanah bahkan ada yang membakarnya. Proses pembakaran sampah secara terbuka dapat menghasilkan polutan, salah satunya partikulat. Pembentukkan partikulat terjadi pada pembakaran tidak sempurna. Misalnya, partikulat yang dihasilkan dari pembakaran sampah adalah padatan dalam gas. Pembakaran sampah pada kondisi pembakaran dan suhu yang rendah dapat menimbulkan gas racun dioksin/furan lebih tinggi daripada insenerator yang terkendali. Dioksin dan Furan dalam jangka panjang dapat menyebabkan kanker, gangguan pada sistem reproduksi dan cacat lahir; sedangkan jangka pendek akan menyebabkan kerusakan hati, kehilangan berat badan, dan penurunan sistem kekebalan tubuh (Warlina, 2008). Agar dapat dikelola dengan 
baik maka perlu pendekatan sosial budaya kepada masyarakat sehingga sampah bisa dikelola dengan mandiri (Widiarti, 2012).

Tujuan dari kegiatan pengabidan ini antara lain: 1) Mensukseskan program Pemerintah Kulonprogo untuk mewujudkan desa bebas sampah; 2) Mensukseskan program Desa Karangsari menjadi desa percontohan smart village; 3) Mendukung pengembangan SDM Desa Karangsari terkait dengan keterampilan pengolahan limbah organik; 4) Terbentuknya UMKM yang bergerak di bidang kerajinan limbah organik; 5) Mewujudkan masyarakat mandiri secara ekonomi dan meningkatkan taraf kehidupan masyarakat.

\section{MASALAH}

Berdasarkan data kependudukan Yogyakarta Jumlah kepala keluarga Desa Karangsari sebanyak 3.584 jiwa. Sampah yang berasal dari rumah tangga baik yang berupa organik maupun anorganik rata-rata menghasilkan minimal $1 \mathrm{~kg}$ sampah perhari. $1 \mathrm{~kg}$ sampah x jumlah kepala keluarga $3.584=3.584 \mathrm{~kg}=3,584$ ton per hari. Jumlah yang cukup fantastik apalagi jika sebagian besar sampah tersebut dibakar.

Pengolahan sampah organik menjadi souvenir dan pupuk perlu segera dicanangkan. Mengingat dampak yang ditimbulkan dari pembakaran sampah sangat berbahaya bagi tubuh dan lingkungan. Pengolahan limbah organik maupun anorganik dapat dilakukan dengan menerapkan care waste industry..

\section{METODE PELAKSANAAN}

Metode yang digunakan dalam kegiatan ini yaitu pendidikan masyarakat dan pelatihan. Kegiatan pendidikan masyarakat yaitu melakukan penyuluhan kepada masyarakat tentang bahaya pembakaran sampah bagi lingkungan dan kesehatan, serta pengolahan limbah organik menjadi kompos padat dan cair. Sedangkan untuk kegiatan pelatihan yaitu melakukan pelatihan tentang pembuatan kompos cair dan padat dari limbah organik.

Durasi kegiatan untuk penyuluhan tentang bahaya pembakaran limbah organik maupun anorganik yaitu 2 x 3 jam x 2 minggu. Sedangkan untuk durasi kegiatan untuk pelatihan pembuatan kompos yaitu 2 x 6 jam x 2 minggu.

\section{HASIL DAN PEMBAHASAN}

Pelaksanaan penyuluhan dan pelatihan pengolahan sampah organik dilaksanakan selama satu bulan di Desa Karangsari pada bulan Agustus 2019. Teknis pelaksanaan 
diawali dengan penyuluhan tentang bahaya pembakaran sampah bagi lingkungan dan kesehatan. Setelah dilakukan penyuluhan kemudian dilakukan pelatihan pembuatan kompos padat dan cari dari limbah organik.

Dari hasil survei didapatkan bahwa sampah yang dihasilkan oleh masyarakat di Desa Karangsari sebagian besar tidak dimanfaatkan atau dibakar begitu saja. Pembuangan sampah rumah sampah di sekitar rumah atau sungai akan mencemari lingkungan. Oleh karena itu perlu dilakukan kajian untuk pengelolaan rumah tangga. Riswan et al. (2011) menyatakan bahwa sampah rumah tangga yang dihasilkan sebanyak 1,46 liter/orang/hari atau sekitar 0,38 kg/orang/hari. Jumlah ini terdiri dari $47 \%$ sampah organik, $15 \%$ sampah kertas, 22\% plastik, dan $16 \%$ logam dan sebagainya. Aktivitas manusia dalam rumah tangga menghasilkan limbah dalam bentuk sampah rumah tangga (Suwahyono, 2014).

Pengelolaan sampah rumah tangga sangat bermanfaat untuk mengurangi timbunan sampah. Pengelolaan sampah rumah tangga ini dapat dilakukan dengan mengolah sampah menjadi barang bermanfaat dan juga menjadi kompos (Marleni, Mersyah \& Brata, 2012). Untuk meningkatkan pengetahuan masyarakat akan manfaat pengelolaan sampah maka dilakukan sosialisai berupa penyuluhan kepada masyarakat Desa Karangsari. Adanya sosialisasi ini diharapkan mampu meningkatkan pengetahuan masyarakat akan manfaat dari mengelola sampah. Jika dikelola secara baik maka dapat mengurangi volume sampah hingga meningkatkan nilai ekonomi dengan daur ulang (Utami, Indrasti \& Dharmawan, 2008). Maka akan bermanfaat bagi masyarakat desa tersebut yang sebagian penduduknya merupakan petani.

Setelah dilakukan sosialisasi kepada masyarakat Desa Karangsari, selanjutnya diadakan pelatihan pembuatan kompos organik dengan harapan ada perubahan perilaku dalam mengeolal sampah. Perubahan tersebut terjadi jika mendapatkan pemahaman yang lengkap terkait pemanfaatan sampah (Dirgantara, 2013). Kegiatan pelatihan pembuatan kompos, sebelumnya masyarakat diberi pelatihan membuat komposter yang nantinya akan digunakan untuk membuat kompos cair dan padat. Langkah dalam pembuatan komposter sebagai berikut: 1) Membuat 2 lubang di sisi kanan dan kiri ember menggunakan bor; 2) membuat 1 lubang di bagian bawah ember, posisi lubang lebih rendah dari lubang sebelumnya. Sekitar 5-10 cm, dari alas ember. Lubang ini dipakai untuk pemasangan kran; 3) Membuat saringan. Saringan bisa menggunakan tutup ember, akrilik, spon bekas keset, atau penyaring. Pada saringan ini diberi lubang kecil-kecil; 4) Pemasangan saringan di bagian bawah. Agar dapat duduk dengan baik, saringan dapat ditambahkan 4 buat kaki dari 
potongan paralon sepanjang 7-15 cm; 5) Untuk meminimalkan komposter menjadi tempat bertelur lalat, maka lubang-lubang udaya yang ada dipasang kain kasa.

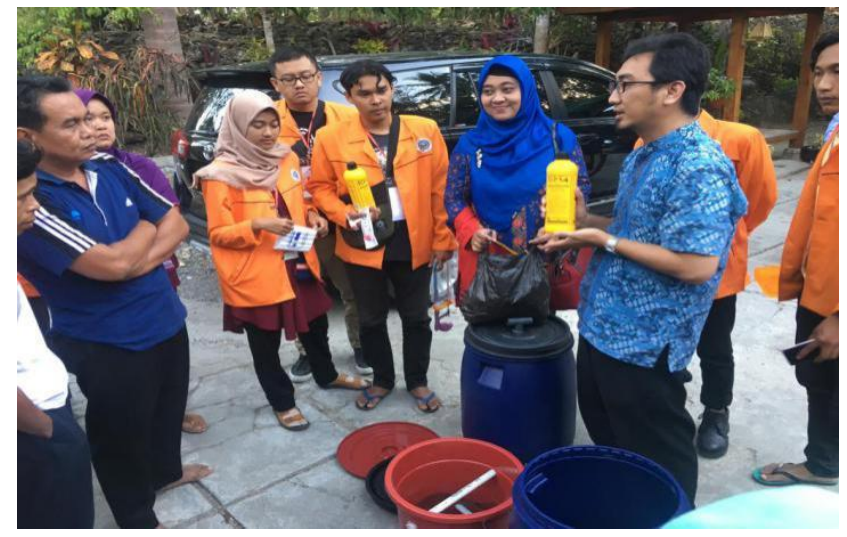

Gambar 1. Pelatihan pembuatan komposter

Kompos merupakan pupuk yang berasal dari proses pelapukan bahan-bahan yang berupa dedaunan, jerami, alang-alang, rumput, kotoran hewan, sampah organik dan lainlain. Pupuk kompos memiliki keunggulan dapat memperbaiki sifat fisik tanah, sifat kimua tanah dan sifat biologi tanah. Hal ini karena karakteristik yang dimiliki antara lain mengandung unsur hara dalam jenis dan jumlah bervariasi tergantung bahan asal, menyediakan unsur hara secara lambat dan dalam sumlah terbatas (Dewi \& Tresnowati, 2012).

Langkah pembuatan kompos padat dan cair sebagai berikut: 1) Potong kecil sampah organik menjadi sekitar 1-2 cm; 2) Masukkan sampah organik yang telah dipotong kecil ke dalam komposter; 3) Semprot/ campur sampah organik dengan bioaktivator/EM4 sampai rata; 4) Lakukan penyemprotan setiap kali memasukkan sampah; 5) Tutup rapat kembali komposter; 6) Diamkan selama beberapa 5-6 minggu.

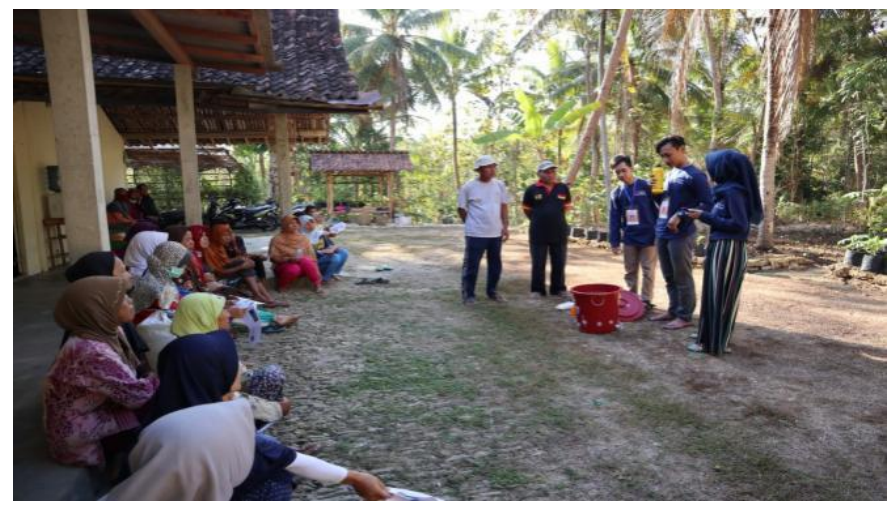

Gambar 2. Pelatihan pembuatan kompos

Kualitas hasil pengomposan dipengaruhi oleh beberapa faktor salah satunya adalah lama waktu pengomposan. Untuk mempersingkat waktu pengomposan maka dalam proses 
pembuatan kompos dimasukkan EM4 sebagai bioaktivator. Semakin besar konsentrasi EM4 maka maka waktu pengomposan semakin cepat (Yuniwati, Iskarima \& Adulemba, 2012). Selama proses pembuatan kompos maka sampah yang sudah dicampur dengan EM4 tadi akan mengalami perubahan warna serta menghasilkan air lindi (kompos cair). Nurjazuli, Asti \& Cut, (2016) mengungkapkan bahwa pada hari ke 7 minggu pertama sampah sudah mulai berubah warna menjadi coklat muda, dan telah terbentuk kompos cair (lindi) yang berwarna kuning kecoklatan. Air lindi yang dihasilkan ini bagian dari proses terjadinya pembusukan sampah. Selama pembuatan kompos juga diperlukan proses pembalikan sampah secara berkala. Pembalikan sampah ini bertujuan untuk memasukkan udara segar sehinggga oksigen yang dibutuhkan oleh mikroba bertambah (Dewi \& Tresnowati, 2012) Jika sampah sudah berubah warna dan tidak memiliki bau maka kompos dinyatakan sudah jadi dan siap untuk digunakan.

Dalam pengelolaan sampah penting adanya partisipasi masyarakat. Pada pengabdian ini masyarakat dilibatkan untuk bersama sama mengelola sampah bekerjasama dengan perangkat desa. Setelah diberikan sosialisasi dan pelatihan maka masyarakat memiliki kemauan untuk mengelola sampah tersebut secara mandiri. Untuk meningkatkan partisipasi masyarkat salah satunya dengan melibatkan kelompok tani yang ada disalah satu dusun Desa Karangsari. Partisipasi masyarakat dalam mengelola sampah perlu dilibatkan terutam di desa kawasan pertanian (Sari, 2016). Kompos yang dihasilkan dapat dimanfaatkan sebagai pupuk untuk tanaman pertanian. Selain bermanfaat secara ekonomi, pengelolaan sampah juga memiliki manfaat lainnya. Antara lain mengurangi pencemaran lingkungan, dan mengurangi pertumbuhan bibit penyakit (Widawati, Tanidjaja, Iskandar, \& Budiono, 2014).

\section{KESIMPULAN}

Pelaksanaan kegiatan penyuluhan dan pelatihan pembuatan kompos sangat membantu masyarakat untuk memanfaatkan limbah atau sampah organik. Kegiatan tersebut dapat mengurangi risiko pencemaran lingkungan dan gangguan kesehatan karena sampah tidak akan dibakar lagi. Kompos yang dihasilkan dari limbah organik ini dapat berupa kompos padat dan cair yang dapat dimanfaatkan oleh masyarakat untuk pupuk. Kegiatan tersebut dapat dikembangkan lagi di berbagai daerah untuk mengurangi pencemaran lingkungan dengan cara pemanfaatan limbah disekitar. Limbah yang semula tidak bernilai dapat dimanfaatkan menjadi kompos dan menjadi barang yang bernilai. 


\section{UCAPAN TERIMA KASIH}

Pemberdayaan masyarakat Karangsari dalam pengiolahan limbah organik merupakan hibah Kemenristekdik Skim KKN-PPM pendanaan tahun 2019. Hibah dari Kemenristekdikti sangat membantu kami dalam melaksanakan tridarma perguruan tinggi yaitu pengabdian kepada masyarakat. Pendanaan yang diberikan sangat bermanfaat bagi masyarakat Desa Karangsari, Pengasih, Kulon Progo, Yogyakarta. Kegiatan KKN-PPM ini juga didukung penuh oleh Lembaga Penelitian dan Pengabdian Masyarakat Universitas Ahmad Dahlan Yogyakarta.

\section{DAFTAR PUSTAKA}

Dewi, Y.S., Tresnowati. (2012). Pengolahan Sampah Skala Rumah Tangga Menggunakan Metode Komposting. Jurnal Ilmiah Fakultas Teknik LIMIT’S, 8(2), 204-214.

Dirgantara, I. M. B. (2013). Pengetahuan Mendaur Ulang Sampah Rumah Tangga dan Niat Mendaur Ulang Sampah. Jurnal Studi Manajemen Dan Organisasi., 10(1), Dirgantara, I.M.B. (2013). Pengetahuan Mendaur Ula.

Marleni, Y., Mersyah, R., Brata, B. (2012). Strategi Pengelolaan Sampah Rumah Tangga di Kelurahan Kota Medan Kecamatan Kota Manna Kabupaten Bengkulu Selatan. Jurnal Penelitian Pengelolaan Sumberdaya Alam Dan Lingkungan, 1(1), 35-40.

Marliani, N. (2014). Pemanfaatan Limbah Rumah Tangga (Sampah Anorganik) sebagai Bentuk Implementasi dari Pendidikan Lingkungan Hidup. Jurnal Formatif, 4(2), 124-132.

Nurjazuli, Asti.A, Cut, J. et. al. (2016). Teknologi Pengolahan Sampah Organik Menjadi Kompos Cair (Organic Waste Treatment Technology Toward Liquid Compost). Prosiding Seminar Nasional Sains Dan Teknologi Lingkungan II. Padang.

Posmaningsih, D. A. A. (2016). Faktor Faktor yang Mempengaruhi Partisipasi Masyarakat Dalam Pengelolaan Sampah Padat di Denpasar Timur. Jurnal Skala Husada, 13(1), 59-71.

Riswan, Sunoko, H. R., \& Hadiyarto, A. (2011). Pengelolaan Sampah Rumah Tangga di Kecamatan Daha Selatan. Jurnal Ilmu Lingkungan, 9(1), 31-38.

Sahil, J., Muhdar M.H.I.A., Rohman, F., Syamsuri, I. (2016). Sistem Pengelolaan dan Upaya Penanggulangan Sampah di Kelurahan Dufa-Dufa Kota Ternate. Jurnal Bio Edukasi, 04(02), 478-487.

Sari, N., Mulasari, S. A. (2017). Pengetahuan, Sikap, dan Pendidikan dengan Perilaku Pengelolaan Sampah di Kelurahan Bener Kecamatan Tegalrejo Yogyakarta. Jurnal Medika Respati, 12(02), 78-84.

Sari, P. N. (2016). Analisis Pengelolaan Sampah Padat di Kecamatan Banuhampu Kabupaten Agam. Jurnal Kesehatan Masyarakat Andalas, 10(02), 157-165.

Susanto, H. DLH Kulon Progo akan Bentuk Bank Sampah Hingga Tingkat Dusun. , (2018). 
Suwahyono, U. (2014). Cara Cepat Buat Kompos dari Limbah. Jakarta: Penebar Swadaya.

Utami, B.D., Indrasti, N.S., Dharmawan, A. H. (2008). Pengelolaan Sampah Rumah Tangga Berbasis Komunitas: Teladan dari Dua Komunitas di Sleman dan Jakarta Selatan. Jurnal Transdisiplin Sosiologi, Komunikasi, Dan Ekologi Manusia, 02(1), 49-68.

Warlina, L. (2008). Estimasi Emisi Dioksin/Furan dan Faktor-Faktor yang Mempengaruhi Konsentrasi Emisi ke Udaya yang Berasal dari Industri Logam. Jurnal Matematika, Sains Dan Teknologi, 11-20.

Widawati, E., Tanidjaja, H., Iskandar, I., Budiono, C. (2014). Kajian Potensi Pengolahan Sampah (Studi Kasus : Kampung Banjarsari). Jurnal Metris, 15, 119-126.

Widiarti, I. W. (2012). Pengelolaan Sampah Berbasi "Zero Waste” Skala Rumah Tangga Secara Mandiri. Jurnal Sains Dan Teknologi Lingkungan, 04(02), 101-113.

Yuniwati, M., Iskarima, F., Adulemba, A. P. (2012). Optimasi Kondisi Proses Pembuatan Kompos dari Sampah Organik dengan Cara Fermentasi Menggunakan EM4. Jurnal Teknologi, 05(02), 172-181. 